\title{
Nineteenth-Century Art Worldwide
}

a journal of nineteenth-century visual culture

Elizabeth Buhe, Petra ten-Doesschate Chu, Isabel L. Taube, and

Gabriel P. Weisberg

Editors'Welcome

Nineteenth-Century Art Worldwide 18, no. 1 (Spring 2019)

Citation: Elizabeth Buhe, Petra ten-Doesschate Chu, Isabel L. Taube, and Gabriel P. Weisberg, "Editors' Welcome," Nineteenth-Century Art Worldwide 18, no. 1 (Spring 2019), https://doi.org/ 10.29411/ncaw.2019.18.1.1.

Published by: Association of Historians of Nineteenth-Century Art

Notes:

This PDF is provided for reference purposes only and may not contain all the functionality or features of the original, online publication.

License:

This work is licensed under a Creative Commons Attribution-NonCommercial 4.0 International License Creative Commons License. 


\section{Editors' Welcome}

With this issue, we say farewell to one of the founding editors of Nineteenth-Century Art Worldwide, Gabriel (Gabe) P. Weisberg. Since the first issue in 2002, he has been the book and exhibition reviews editor and has exposed thousands of readers to hundreds of books and exhibitions-some highly visible, others unjustly neglected-all interesting and worth knowing about. We owe him enormous gratitude for having set the highest standards for the $N C A W$ reviews and having made them the "go-to" source for in-depth and intelligent assessments of books and exhibitions of nineteenth-century art.

During most of his seventeen years as book and exhibition reviews editor, Gabe has been assisted by Janet Whitmore, who is retiring from $N C A W$ with him. Together, they made a wonderful team, resourceful and efficient, always ready with the reviews well before our publication deadline. We wish them both well, happy in the knowledge that they will remain closely affiliated with $N C A W$.

Gabe's successor is David O'Brien, professor of art history at the University of Illinois, Urbana-Champaign. A graduate of Harvard (AB) and the University of Michigan (MA, PhD), David is a specialist in early nineteenth-century French art, having published books on JeanAntoine Gros and Eugène Delacroix. His outlook on art history, however, is much broader than the subjects of these monographs would lead us to believe. His edited volume, Civilisation and Nineteenth-Century Art: A European Concept in Global Context (Manchester University Press, 2016) deals with the ways in which the concept of civilization was rendered in nineteenth-century painting and sculpture in Europe and the United States, often against the backdrop of Western depictions of non-Western cultures. Its perspective is worldwide, as is the point of view of many of his articles. In this respect, he embraces the aims of NCAW and is a fitting successor to Gabe, whose outlook on nineteenth-century art was likewise broad and inclusive.

We welcome David and look forward to a long and fruitful collaboration. 